\title{
PULP AND PAPER POTENTIALS OF PLANTAIN PSEUDOSTEM
}

\author{
B.O. Ogunsile ${ }^{1}$, M.A. Omotoso ${ }^{1}$ and M.A. Onilude ${ }^{2}$ \\ ${ }^{1}$ Department of Chemistry, University of Ibadan, Nigeria \\ ${ }^{2}$ Department of Agricultural Engineering, University of Ibadan, Nigeria
}

\begin{abstract}
The fiber characteristics, chemical properties and pulping potentials of plantain pseudostem (Musa paradisiaca) were examined to assess its suitability as a raw material for the pulp and paper industry. The pseudostem was delignified under the soda pulping processes at liquor to solid ratio of 10:1. The pulp yields and residual lignin contents were determined under varied operational conditions. The specific gravity was within the low density classification. The fibers were on the average $4.2 \mathrm{~mm}$ long, $31.5 \mathrm{~mm}$ wide and $6.1 \mathrm{~mm}$ thick. The pseudostem was characterized by $3.4 \%$ ash, $7.4 \%$ lignin, $48 \%$ cellulose and high extractive contents. Prolonged cooking at a low temperature resulted only in a small increase in the total pulp yield over that obtained at a high temperature for the same degree of pulping. The selectivity of lignin dissolution was independent of the working conditions.
\end{abstract}

Keywords: Musa paradisiaca, fiber dimension, chemical composition, soda pulping.

\section{INTRODUCTION}

In many communities of the world, available lands surrounding the society are usually developed for the production of food crops to meet local consumption. Relatively large amounts of agricultural residues and non-wood materials are produced along side the food crops. It has been estimated that the amount of secondary fibers being produced annually is about 2500 million tons (Diesen, 1998). This amount is quite substantial when compared with the general annual paper consumption. Therefore the utilization of these non-wood fibers may help solve the in- creasing cost of pulpwood and the anticipated rise in fiber shortage in the future. Towards this end, researches have been geared towards increasing the number of non-wood plants, majority of which have already found commercial use (Ray, 1990). For instance non-wood fibrous plants such as flax, hemp, cotton miscanthus, kenaf and esparto are potential crops for the paper industry in different European countries (van Dam et al., 1994). Other non-wood plants that have been considered include mazri (Mohammed, 1994), sorghum (Belayachi and Delmas, 1995), bagasse (Goncalves et al., 1998), 
switch grass (Law et al., 2001), and wheat straw (Jimenez et al., 2002).

Musa paradisiaca (plantain) is an important food crops widely cultivated in South-Western Nigeria. The plant matures much faster than wood. Since its introduction into the continent, several factors among which are natural hybridization, somatic mutation and evolutionary development have given rise to a large diversity of cultivars in Africa. More than 20 cultivars have been reported in Nigeria alone. The rainfall and soil condition that prevail in South-Western Nigeria make the production of more species profitable (Ogazi, 1996). The development of new hybrids at the Nigerian Institute of Horticultural Research (NIHORT) and International Institute of Tropical Agriculture (IITA) will go a long way at boosting their production in view of their high yield and resistance to diseases. After the fruits are harvested, the pseudostems are left to decay and rot thereby constituting pollution and waste disposal problems. In this study, we examined the fiber characteristics, chemical properties, and the pulping potentials of plantain pseudostem under the soda pulping processes as a way of utilizing this agricultural waste for pulp and paper production.

\section{MATERIALS AND METHODS}

Plantain pseudostems whose fruit had just been harvested were collected at the Department of Agronomy of the University of Ibadan. The pseudostems were cut into chips, sun-dried and stored at room temperature in a polythene bag. The specific gravity was determined in accordance with the ASTM standard procedure.

\section{Fiber Dimension}

Some representative chips of the plantain pseudostems were reduced to splints of about 20 $40 \mathrm{~mm}$ and placed in a mixture of equal volume of glacial acetic acid and $50 \%$ hydrogen peroxide in a covered bottle. The macerated splints were disintegrated by shaking to release the fibers, which were prepared on a slide. The fiber length (L), fiber diameter (D), lumen width (d), and cell wall thickness of 60 fibers were measured under a Reichert visopan projector. The following morphological indices were determined from these measurements:

$$
\begin{aligned}
\text { Slenderness ratio } & =\mathrm{L} / \mathrm{D} \\
\text { Flexibility coefficient }(\%) & =(\mathrm{d} / \mathrm{D}) \times 100 \\
\text { Where: } \quad \mathrm{L} & =\text { Fiber length } \\
\mathrm{D} & =\text { Fiber diameter } \\
\mathrm{d} & =\text { Lumen width } \\
\mathrm{CWT} & =\text { Cell wall thickness }
\end{aligned}
$$

\section{Chemical Analysis}

The proportions of the chemical constituents that affect the characteristics of the plant were determined on ground samples of the pseudostem chips using standard methods (ASTM and TAPPI). Soda cooking liquor was prepared from a standard concentrated solution of sodium hydroxide by serial dilution with de-ionized water.

\section{Pulping Experiment}

The samples were pulped in a 10-liter electrically heated stainless steel digester. Chips from plantain pseudostem were weighed and charged into the digester with the required amount of chemical solution at liquor to solid of 10:1. The digester was heated to the operating temperatures $\left(150^{\circ} \mathrm{C}\right.$ and $\left.170^{\circ} \mathrm{C}\right)$ and time $(30,90$ and 150 minutes), which was then maintained throughout the experiment. The resulting pulp was thoroughly washed with tap water and the pulp yield was determined gravimetrically after drying at $102^{\circ} \mathrm{C}$ to constant weight in the oven. The pulps were analyzed for Kappa number as described in TAPPI standard. The Residual Klason Lignin (RKL) was estimated from the Kappa number by multiplying with a factor of 0.13 (TAPPI, 1993).

\section{RESULTS AND DISCUSSION}

\section{Fiber Dimension}

Table 1 gives the result of the specific gravity and the fiber dimension of the plantain pseudostem. The specific gravity of 0.29 is within the low value classification of 0.20 to 0.40 (Chittenden and Palmer, 1990). This implied that 
the problem associated with wearing or tearing of chipper knives due to excessive chipping might not be encountered with the pseudostem. However, large volume of materials would be needed for pulping because of it bulkiness. The average fiber length was $4.2 \mathrm{~mm}$ similar to those of medium to long fibered plant (Hurter, 1988).

Table 1: Specific gravity, fiber characteristics and morphological indices of plantain pseudostem

\begin{tabular}{lr}
\hline Component & \multicolumn{1}{c}{ Amount } \\
\hline Specific gravity & $0.29 \pm 0.03$ \\
Fiber dimensions & \\
Fiber length $(\mathrm{mm})$ & $4.17 \pm 1.2$ \\
Fiber diameter $(\mu \mathrm{m})$ & $31.3 \pm 7.7$ \\
Lumen width $(\mu \mathrm{m})$ & $19.4 \pm 7.0$ \\
Fiber wall thickness $(\mu \mathrm{m})$ & $6.1 \pm 1.9$ \\
Flexibility coefficient & $60.7 \pm 11.4$ \\
Slenderness ratio & $135 \pm 38.5$ \\
\hline
\end{tabular}

This indicates that strong papers would be produced from the plant because a strong relationship exists between the strength properties of paper and the fiber length constituting it (Ververis et al., 2004). The fiber diameter, lumen width, cell wall thickness, fiber slenderness and flexibility coefficient were in the medium range, comparable to typical dimension of paper making fibers. The pseudostem could be expected to exhibit average bonding and fiber strength (Ververis et al., 2004).

\section{Chemical Characteristics}

The results of the chemical composition are presented in Table 2. The ash content was $3.44 \%$. This is desirably low compared to $14 \%$ reported for some banana crops elsewhere (Noronha et al., 1999). Low ash content will not affect normal chemical consumption during pulping or give problems at waste liquor recovery.

The extractive contents, that is, hot water soluble $(18.7 \%), 1 \%$ caustic soda $(35.5 \%)$ and alcohol-
Table 2: Chemical Composition of Plantain pseudostem

\begin{tabular}{lc}
\hline Component & $\begin{array}{c}\text { Amount (\% oven } \\
\text { dry weight }\end{array}$ \\
\hline Ash & $3.4 \pm 0.7$ \\
Extractives & $18.7 \pm 0.06$ \\
Hot water & $35.5 \pm 0.18$ \\
$1 \% \mathrm{NaOH}$ & $12.8 \pm 2.68$ \\
Alcohol-benzene (1:2) & $6.3 \pm 0.06$ \\
Lignin & $1.0 \pm 0.06$ \\
Klason lignin & $48.0 \pm 0.3$ \\
Soluble lignin & Cellulose
\end{tabular}

benzene content $(12.8 \%)$ is relatively high but within the range reported for some annual plants such as sweet sorghum (Belayachi. and Delmas, 1995), switch grass Law et al, 2001), and sunflower (Kristova et al., 1998). The high extractives might be attributed to easy access and degradation of cell wall materials on one hand and the presence of high percentage of phenolic and soluble polysaccharides, gums and colouring matter on the other hand. The low lignin content (Klason and soluble lignin), $7.35 \%$, is an indication of easy delignification, short pulping cycle and low chemical consumption. The cellulose content, $48 \%$, predicted moderately high pulp yield.

\section{Pulp Yields and Residual Lignin}

The yield versus time plots showing the effects of the process variables on the pulp yields and residual lignin are presented in Figure 1 and 2. In Figure 1, as expected, there was a general decrease in the pulp yield, caused by an increase in the pulping time at a constant temperature and alkali charge. At a particular charge of effective alkali, pulping for 150 minutes at $170^{\circ} \mathrm{C}$ resulted in the lowest yield while the highest yield was recorded for the pulp made for 30 minutes at $150^{\circ} \mathrm{C}$. As it is common with most lignocellulosic materials, two different phases are recognized with respect to the rate of dissolution of initial material (Iglesias et al., 1996). 


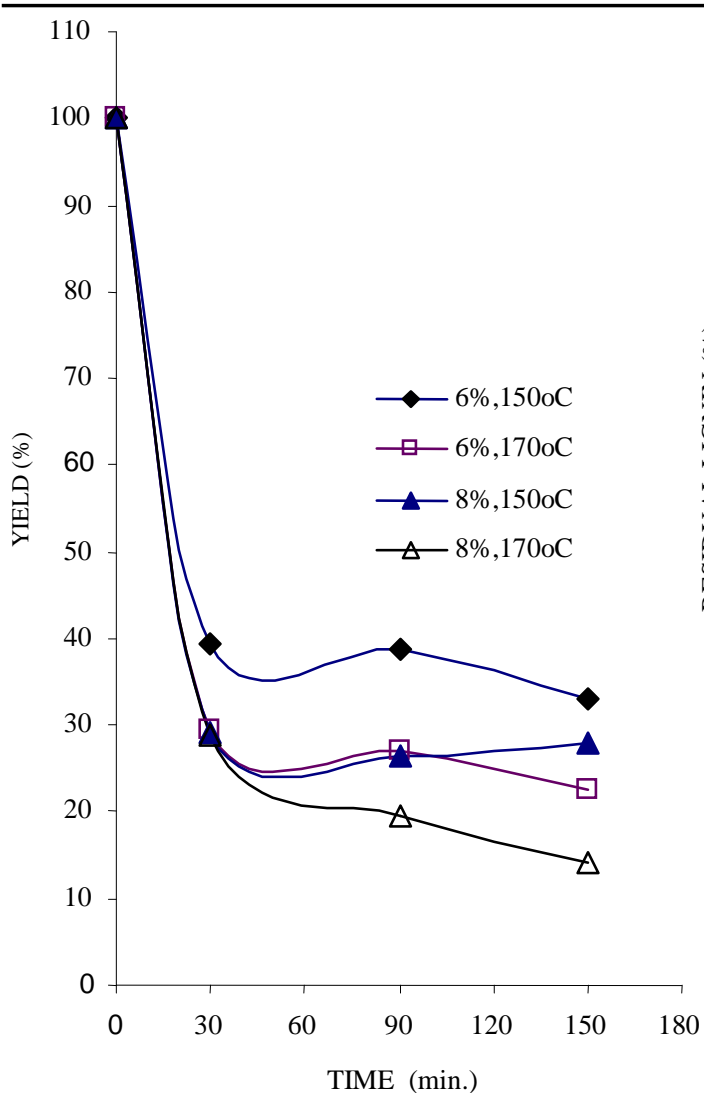

Fig. 1: Effect of temperature and time on pulp yield

The first phase called the easily soluble phase occurred predominantly in the first few minutes of the pulping (about 30 minutes). This is followed by the second phase, the less easily soluble phase, which proceeds at a slower rate. More than half of the initial material dissolved in the rapid phase. This may be attributed to the high extractive contents of the pseudostem.

Figure 2 shows the residual lignin versus time plots. The rate of delignification increases with time as temperature and pulping liquor is increased. As observed with pulp yield, here also two process of lignin dissolution are observed.

This could be caused by two different fractions:

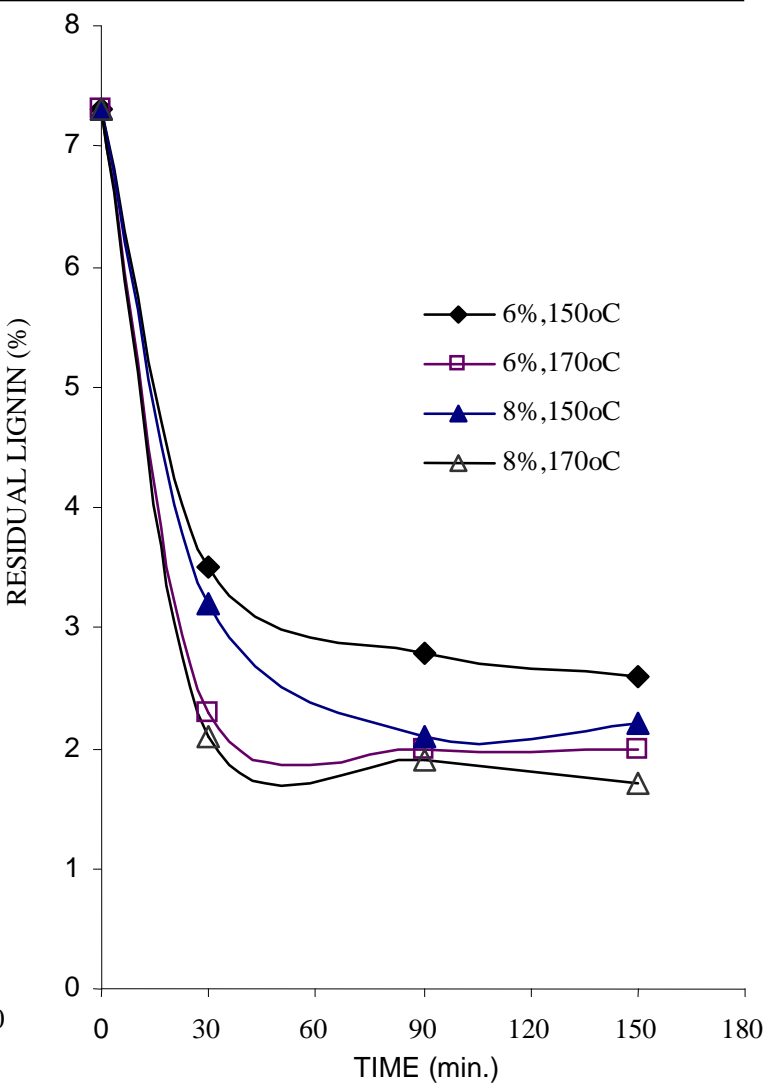

Fig. 2: Effects of temperature and time on residual lignin

easy (or fast) solubilization and difficult (or slow) solubilization (Kristova et al., 1998). The existence of such phases of delignification is a common behaviour with other pulping systems using different agents and methods (Currelo et al., 1995; Young 1989; Labidi et al., 1993) and seems to be related to the dissolution of lignin fractions of different structural origin in vegetable tissues. In the opinion of katzen (1980) the initial phase of fast or bulk delignification is regarded as caused by the rapid initial swelling of lignocellulosic residue in the pulping liquor and subsequent rapid hydrolysis of the polysaccharide exposed, and corresponding solubilisation of the exposed lignin. In the latter stage

162 Journal of Science and Technology, Vol. 28, No. 3, Dec., 2008 
polysaccharide and lignin exposure is slow, thus the rate of delignification are much smaller even when the treatment duration are extended.

During pulping, both lignin and the carbohydrates are dissolved at different rates. It seems that at $6 \%$ soda and $150^{\circ} \mathrm{C}$, the rate at which the pseudostem is being converted to pulp is higher than the rate at which pulp is being dissolved out. However an increase in alkali or temperature consequently increases the rate of deligninfication, and so the pulp dissolved almost as it is being formed. The results also showed that prolong cooking time in the presence of high alkali charge and temperature would seriously dissolve the pulp. From the point of view of high pulp yield, it is more advisable to employ mild cooking conditions.

The selectivity graph was expressed as the loga- rithmic of the product of the yield and RKL, versus the logarithmic of RKL (Masura, 1993). The result as illustrated in Figure 3 showed that the selectivity of lignin dissolution was independent of the working.

The good correlation $\left(\mathrm{r}^{2}=0.87\right)$ will allow the establishment of quantitative estimations between the yield and RKL within the range studied.

\section{CONCLUSION}

Available data emanating from this study revealed that plantain pseudostem has good potential for pulp and paper production. It average fiber length was similar to medium to long fibered plants. It is expected to exhibit high bonding and fiber strength. The low lignin content was an indication of easy delignification, short

Fig 3: Selectivity graph for soda pulping of plantain pseudostem conditions

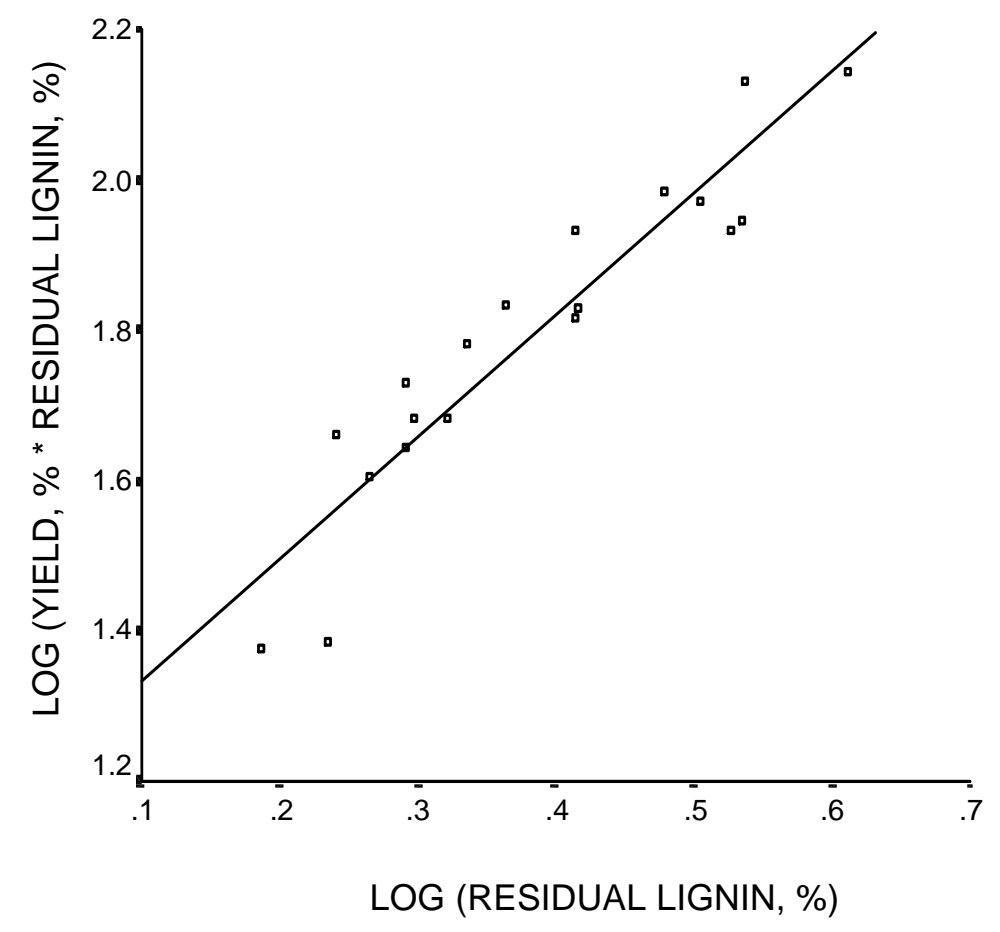


pulping cycle and low chemical consumption. The selectivity of lignin dissolution was independent of the working condition. The pseudostem was delignified to half its original lignin content in the first 30 minutes of cooking at a relatively low concentration of cooking liquor and temperature. However, prolong cooking time in the presence of high alkali charge and temperature seriously dissolved the pulp.

\section{ACKNOWLEDGEMENT}

The authors are grateful for the technical assistance rendered by Messrs S. Kamoru and S. Ibitoye of the then Laboratory Technology Training School, University of Ibadan, Ibadan, Nigeria.

\section{REFERENCES}

ASTM International (American Society for Testing and Materials): Standard method of tests for water solubility Method A and B, (1968), D1110-56; specific gravity of wood and wood -base materials designated, Method b, volume by Immersion, (1969), D 2395-69; ash, (1972), D1102-56; alcoholbenzene solubility, (1972), D1107-56; one percent caustic soda solubility, (1972), D1109-56, and moisture in wood, (1977), D1101-56;

Belayachi, L. and Delmas, M. (1995). Sweet sorghum bagasse : A raw material for the manufacture of chemical paper pulp. Biomass and Bioenergy 8 (6): 411-417.

Chittenden. A.E. and Palmer, E.R. (1990). Pulping characteristics of five low density wood species grown in Belize. Tropical Science 30: $167-177$.

Currelo, A.A.S., Aranjo, E.S. and Sansigolo, C.A. (1995). Kinetics of organosolvent pulping of Euclyptus globulus. International symposium on wood pulping chemistry; Finland. 2: 213-218.

Diesen, M. (1998), World paper markets. In: Diesen M. [Editor] Papermaking Science and Technology. Helsinki, Finland: Fapet Oy.
Goncalves A.R., Esposito, E. and Benar P. (1998). Evaluation of Panus tigrinus in the deligninfication of sugarcane bagasse by FTIR-PCA and pulp properties. Journal of Biotechnology. 66: 177-185.

Hurter, A.M. (1988). Utilization of annual plants and agricultural residues for the production of pulp and paper. Proceedings of TAPPI pulping conference 1988. New Orleans, LA. USA . Book 1: 139-160.

Iglesias G., Bao, M. Lamas J and Vega, A. (1996). Soda pulping of Miscanthus sinensis: Effects of operational variable on pulp yield and lignin solubilization. Bioresource Technology. 58: 17-23.

Jimenez, L., Perez I., Garcia. J.C., Rodoriguez, A. and Ferrer, J.L. (2002). Influence of ethanol pulping of wheat straw in the resulting paper sheets. Process Biochemistry 37: 665-672.

Katzen, R., Frederickson, R. and Brush, B.F. (1980). The alcohol pulping and recovery process. Chemical Engineering Progress. 76(2): 62-67.

Kristova, P., Gabir, S., Bentcheva, S. and Dafalla, S. (1998). Soda-anthraquinone pulping of sunflowers stalks. Industrial Crops and Products. 9: 9-17.

Labidi, A., Robert, D. and Pla, F. 1993. Alkaline delignification of hardwoods in a flow through reactor working at a low residence time. Holzforschung. 47: 213-218.

Law, K.N., Kokta, B.V. and MaO, C.B. (2001). Fiber morphology and soda - sulphite pulping of switchgrass. Bioresource Technology. 77: 1-7.

Masura, V. (1993). A mathematical model for kraft pulping expressed by a logarithmic straight-line equation. TAPPI Journal. 76 (11): 105-109.

Mohammed Ayaz. (1994). Anatomy and suitability of Mazri [n. ritchieana] for pulp and

164 Journal of Science and Technology, Vol. 28, No. 3, Dec., 2008 
paper based on fiber characteristics. Pakistan Journal of Forestry. 44(3): 135-141.

Noronha, R., Cordeiro, N. Belgacem, M.N., Costraw, A.P. and Silvy J. (1999). Banana wastes as a source of lignocellulosic fibers for papermaking. Proceedings of pre- symposium of the $10^{\text {th }}$ international symposium on wood and Pulp Chemistry, Seoul, South Korea, pp. 286-290.

Ogazi, P.O. (1996). Plantain: Production Processing and Utilization. Paman and ssociates Ltd. Nigeria, p.21.

Ray, A.K., Bonsal, M.C., Rao, N.J. and Mohanty, B. (1990). New pulping process for non-conventional raw materials. Non-woods Plant Fiber Pulping Progress Report 20: 177 $-189$.

Technical Association of the Pulp and Paper Industry, (TAPPI), 1998. Acid - insoluble lignin in wood and pulp-T22 om-98. 169.
Technical Association of Pulp and Paper Industry, TAPPI. (1993). Kappa number of pulp T236CM -85.

Van Dam, J., Vilsteren, G., Zomers, F., Shannom, W. and Hamilton, I. (1994). Industrial fiber crops. Directorate-General XII, Science Research Development. ATO-DLO, Wageningen.

Ververis, C., Georghiou, K., Christodoulakis, N., Santas, P., and Santas, R. (2004). Fiber dimensions, lignin and cellulose content of various plant materials and their suitability for paper production. Industrial Crops and Products 19 (3): 245-254.

Young, R.A. (1989). Ester pulping: A status report. TAPPI Journal, 72 (4): 195-200. 